Body satisfaction

Ogden, J., Mundray, K. (1996). The effect of the media on body satisfaction: the role of gender and size, European Eating Disorders Review 4, 171-182.

The effect of the media on body satisfaction:

the role of gender and size.

Jane Ogden and Kate Mundray

Jane Ogden, PhD., Kate Mundray BSc, United Medical and Dental Schools of Guy's and St

Thomas's, London.

Address correspondence to Dr Jane Ogden, Lecturer in Health Psychology, Department of

General Practice, United Medical and Dental Schools of Guy's and St Thomas's, London

University, 80 Kennington Road, London, SE11 6SP, U.K.

THE MEDIA AND BODY SATISFACTION 
Body satisfaction

\begin{abstract}
Media images of stereotypically attractive women are often cited as contributory factors in body size distortion and body dissatisfaction. In fact, recent research suggests that acute exposure to such images may exacerbate body distortion in women with eating disorders. The present study examined the effects of acute exposure to images of stereotypical attraction (thin pictures) compared to images of overweight individuals (fat pictures) in both men and women. 20 men and 20 women completed measures of body satisfaction before and after viewing images of either thin or overweight individuals matched for the subject's gender. The results suggested that subjects of both gender reported feeling less satisfied with their bodies as measured by rating scales (eg. feeling fat, feeling attractive), body silhouettes and body size estimation, after viewing the thin pictures and showed improved body satisfaction after viewing the overweight pictures. The results also suggested that this response was greater in the female than in the male subjects for some of the measures (eg. feeling fat, feeling toned) and was unrelated to levels of restrained eating. The results are discussed in terms of the role of the media in determining body image and the possible use of such images in clinical practice.
\end{abstract}


Body satisfaction

\section{The effect of the media on body satisfaction: the role of gender and size.}

Body dissatisfaction is a common characteristic of many women (Cooper, Taylor, Cooper and Fairburn, 1987). It expresses itself behaviourally in terms of attempts to restrain food intake and episodes of overeating (Herman and Mack, 1975., Herman and Polivy, 1984., Ogden and Wardle, 1991., Ogden, 1992). It is also expressed in discrepancies between perceived and desired body size and in feeling fat (Brennan and Kevany, 1985., Counts and Adams, 1985., Carroll, Gleeson, Ribsby and Dugdale, 1986., Thompson and Thompson, 1986). In addition, body size overestimation and body size distortion has been shown when measured using a visual size estimation apparatus (Slade and Russell, 1973., Halmi, Goldberg and Cunningham, 1977) and a body image marking technique (Pierloot and Houben, 1978., Wingate and Christie, 1978., Bowden, Touyz, Rodriguez et al., 1989., see Hsu and Sobkiewicz, 1991 for a comprehensive review). Research also indicates that women who express concerns for their body shape selectively process words relating to body size (Ben-Tovim, and Walker, 1991., Fairburn, Cooper, Cooper et al, 1991., Ogden and Greville, 1993).

Concerns about weight and shape are traditionally associated with women. Research indicates that women are more likely than men to engage in both safe and dangerous food restriction strategies, to show a discrepancy between their real and ideal weight, to have actively dieted during the past six months, to participate in organised weight loss programmes and to prefer to be thinner (Brodie, Slade and Riley, 1991., Rozin and Fallon, 1988., Klesges, Mizes and Klesges, 1987., Jeffrey, Adlis, Forster, 1991). In addition such gender differences are also apparent in children aged 12 to 13 years (Wardle and Beales, 1986) and even as young as 9 years (Hill, Draper, Stack, 1994). However, although compared to women, men's body 
Body satisfaction

satisfaction appears high, research indicates that some men do diet, are aware of cultural norms of male attractiveness, are concerned with physical attractiveness, upper body strength and physical condition and report a preferred size which is different to their perceived shape (Brodie, Slade and Riley,1991., Rozin and Fallon, 1988., Klesges, Mizes and Klesges, 1987., Jeffrey, Adlis, Forster, 1991, Franzoi and Shields, 1984).

Theories of body dissatisfaction include psychodynamic, gender and sexuality perspectives (eg. Bruch, 1974., Orbach, 1978). In addition, many books and papers suggest that media stereotypes play a central role in creating and exacerbating body dissatisfaction. It is suggested that comparisons between the self and media ideals creates dissatisfaction and 'shame' (Silverstein, Streigel-Moore and Rodin, 1987., Garner et al, 1980., Morris, Cooper and Cooper, 1989) and that media stereotypes create and perpetuate the association between ideals of thinness and positive attributes such as a sense of control, success and attractiveness (eg. Glassner, 1988., Brownell, 1991., Ogden, 1992). In addition, the media is deemed responsible for the association between fatness and negative attributes of self indulgence, lethargy and slovenliness (eg. Glassner, 1988., Ogden, 1992). The increased prevalence of dieting behaviour has been related to the decreased size of fashion models (Morris, Cooper and Cooper, 1989) and the differences between Ruben's women and models of the late 20th century are often cited as possible reasons for the increase in eating disorders (eg. Agras and Kirkely, 1986., Morris, Cooper and Cooper, 1989., Brownell, 1991).

Recent research suggests that acute exposure to media images increases body size distortion in anorexics, bulimics and pregnant women compared to neutral images (Waller, Hamilton, Shaw, 1992., Sumner, Waller, Killick, Elstein, 1993., Hamilton and Waller, 1993). The aim 
Body satisfaction

of the present study was to compare the effects of acute exposure to images of stereotypical attractiveness (thin pictures) in both men and women and to contrast this with changes following images of overweight individuals (fat pictures). It was predicted that women would be more sensitive to the media images than men and that the thin pictures would have a more detrimental effect on measures of body satisfaction than the thin pictures.

\section{Methodology}

\section{Subjects}

40 medical students (20 males and 20 females) from London medical schools, whose ages ranged from 19-25 took part in the study.

\section{Design}

The study consisted of both a between and within subject design with two conditions. The between subject variable was gender (male vs female) and the within subject variables were time (time1 (before), time 2 (after)) and condition (thin pictures vs fat pictures). All subjects took part in the study twice and completed a set of measures before (time 1) and after (time 2) exposure to a set of either thin pictures (condition 1) or fat pictures (condition 2) of individuals matched to the subject's gender. The order of the two conditions was counterbalanced across the subjects and the time interval between the conditions ranged from 4 to 10 days.

\section{Procedure}

Subjects completed the following set of measures before and after the experimental manipulation.

\section{Measurements}


Body satisfaction

1) Body satisfaction;

i) visual analogue scales - subjects were asked to rate the following questions for how they were feeling at that precise moment in time on a scale from 'Not at all' (0 mm) to 'Very' (100 mm): i) How fat do you feel? ii) How sexy do you feel? iii) How attractive do you feel? iv) How well toned do you feel? v) How fit do you feel? These items were selected as representative of facets of body satisfaction that were appropriate to both men and women. The interpretation of these items was left to the subjects themselves.

ii) silhouettes - subjects were given 2 sets of body silhouettes ranging from extremely thin (1) to extremely obese (12) which were matched to the subject's gender (Furnham and Alibhai, 1983., Furnham and Radley, 1988). They were asked to rate one set for 'how they felt they looked like at that precise moment' (now score) and the other set for 'how they would prefer to look like' (preferred score). A body satisfaction score was computed (preferred score - now score).

\section{2) Body size estimation}

Body size estimation was measured by using the image marking method (Askevold, 1975) which has been reported to differentiate anorexics from controls (Pierloot and Houben, 1978., Wingate and Christie, 1978., Bowden et al., 1989). Subjects stood in front of a large sheet of acetate and were asked to estimate, by marking points or lines, the width corresponding to their

i) Chest / Bust ii) Waist and iii) Hips.

\section{Experimental Manipulation}

Subjects in each condition were asked to examine five pictures, matched for the subject's 
Body satisfaction

gender, for five minutes. In order to focus their attention onto the stimuli they were asked to rate each picture using visual analogue scales for characteristics such as fatness, attractiveness and sexiness.

\section{Thin pictures (condition 1)}

5 magazine photographs of female or male fashion models representing stereotypical attractive bodies were used for the thin picture condition. The images used were considered to represent the cultural ideal for each gender and portrayed women and men with varying degrees of exposed body.

\section{Fat pictures (condition 2)}

5 magazine photographs of overweight bordering on obese males and females were used for the fat picture condition. The images used were considered to represent unattractive body size, but were matched as closely as possible to the thin pictures in terms of facial expression to avoid any mood effects and body exposure.

\section{$\underline{\text { Profile questionnaires }}$}

After both conditions, subjects completed the following questionnaires:

1) Restrained eating section of the Dutch Eating Behaviour Questionnaire (DEBQ, Van Strien et al., 1986., Ogden, 1993). This was included to examine the role of restrained eating on responses to the media images.

2) Body Shape Questionnaire (BSQ, Cooper, Taylor, Cooper and Fairburn, 1987).

This was included further to describe the subjects. 
Body satisfaction

\section{Results}

The subjects profile characteristics were analysed using ANOVA (SPSSPC). The repeated measures data was analysed using MANOVA (SPSSPC) with subject's gender as the between subject variable (male vs female) and condition (thin pictures vs fat pictures) and time (time 1 (before), time 2 (after)) as the within subject variables. In order to clarify the three way interactions (gender by condition by time interactions) post hoc tests were carried out on the significant interactions to evaluate differences in the way that male and female subjects responded to the two conditions. (To account for the problem of multiple comparisons, only $\mathrm{p}$ values less than 0.01 were accepted). The results were also analysed to assess the role of restrained eating in predicting changes to the images.

\section{Subject Characteristics}

The profile characteristics for all subjects are shown in Table 1.

- Insert Table 1 about here -

Male and female subjects were comparable in age, the female subjects showed a significantly higher level of restrained eating level $(\mathrm{F}[1,38]=16.68, \mathrm{p}<0.001)$ and a significantly higher level of body dissatisfaction $(\mathrm{F}[1,38]=35.64, \mathrm{p}<0.001)$ than the males.

\section{Effect of Experimental Manipulation}

1/ Body satisfaction:

i) visual analogue scales - the means of the visual analogue rating scores for males and females are shown in Table 2. 
Body satisfaction

- Insert Table 2 about here -

a) feeling fat - the results showed main effects of gender $(F[1,38]=9.89, p<0.01)$, of condition $(\mathrm{F}[1,38]=3.78, \mathrm{p}<0.05)$ but no main effect of time. Examination of the means suggested that the female subjects rated themselves as feeling fatter than the male subjects overall and that all subjects rated themselves as feeling fatter in the thin picture condition than in the fat picture condition. The results also showed a significant condition by time interaction $(\mathrm{F}[1,38]=18.07$, $\mathrm{p}<0.0001)$ and a significant gender by condition by time interaction $(\mathrm{F}[1,38]=10.17, \mathrm{p}<0.005)$. The means indicated that all subjects rated themselves as feeling fatter after viewing the thin pictures and thinner after the viewing the fat pictures and that these changes to the pictures were greater in the female subjects than in the male subjects. This was supported by the post hoc tests with only the female subjects showing a significantly different profile of response to the two conditions $(\mathrm{p}<0.001)$.

b) feeling sexy - the results showed a main effect of gender $(F[1,38]=6.45, p<0.01)$, but no main effects of condition or time. The means indicate that males felt more sexy than females in general. The results also showed a significant condition by time interaction $(\mathrm{F}[1,38]=9.56$, $\mathrm{p}<0.005)$ but no significant gender by condition by time interaction. The means suggested that regardless of gender the subjects responded differently to the two conditions and rated themselves as being less sexy after viewing the thin pictures and more sexy after viewing the fat pictures. This profile of response was similar for both male and female subjects.

c) feeling attractive - the results showed no main effects of gender, condition or time. The 
Body satisfaction

results showed a significant condition by time interaction $(F[1,38]=18.40, \mathrm{p}<0.001)$ but no gender by condition by time interaction. Therefore, regardless of gender, all subjects rated themselves as more attractive after exposure to the fat pictures and less attractive after exposure to the thin pictures.

d) feeling toned - the results showed significant main effects of gender $(F[1,38]=7.99, p<0.01)$, condition $(\mathrm{F}[1,38]=16.67, \mathrm{p}<0.001)$ and time $(\mathrm{F}[1,38]=16.48, \mathrm{p}<0.001)$ suggesting that overall females rated themselves as feeling less toned than males and that all the subjects rated themselves as feeling more toned in the fat picture condition than in the thin picture condition. The results also showed a significant condition by time interaction $(F[1,38]=17.22, p<0.001)$ and a significant gender by condition by time interaction $(F[1,38]=5.73, \mathrm{p}<0.01)$. Examination of the means suggests that regardless of gender, all subjects rated themselves as feeling less toned after seeing the thin pictures and more toned after seeing the fat pictures and that this change was greater in the female than the male subjects. This difference between the male and female subjects was supported by the post hoc tests which revealed a significant difference in the female subjects' responses to the two conditions $(\mathrm{p}<0.001)$ and no difference in the male responses.

e) feeling fit - the results showed significant main effects of gender $(F[1,38]=4.96, p<0.05)$ and condition $(\mathrm{F}[1,38]=9.02, \mathrm{p}<0.005)$, but no main effect of time indicating that overall males rated themselves as feeling fitter than females and all the subjects felt fitter in the fat picture condition than in the thin picture condition. The results also showed a significant condition by time interaction $(\mathrm{F}[1,38]=20.74, \mathrm{p}<0.001)$ but no gender by condition by time interaction . The means suggest that regardless of gender all subjects rated themselves as feeling fitter after 
Body satisfaction

exposure to the fat pictures and less fit after exposure to the thin pictures with this different profile of responses to the two conditions being similar in both male and female subjects.

ii) Silhouettes - the means for the body silhouette scores 'now' and 'prefer' and the difference between the two are shown in Table 3.

- Insert Table 3 about here -

i) Picture now - the results showed no main effects of gender, condition or time. However, the results did show a significant condition by time interaction $(F[1,38]=10.01, p<0.005)$ but no gender by time by condition interaction. Examination of the means suggested that regardless of gender, subjects responded differently to the two conditions and felt thinner after viewing the fat pictures and fatter after viewing the thin pictures.

ii) Picture prefer - analysis showed a trend for a main effect of gender $(F[1,38]=3.41, p=0.07)$ but no main effects of condition or time with the means suggesting that females wanted to be thinner than males. Analysis showed no significant interactions for ratings of the subjects preferred body size.

iii) Body satisfaction (prefer-now; the closer the score is to zero the higher the body satisfaction. A negative score indicates a desire to be thinner and a positive score indicates a desire to be fatter).

Analysis showed a significant main effect of gender $(\mathrm{F}[1,38]=8.46, \mathrm{p}<0.005)$ but no main effect of either condition or time suggesting that the female subjects have a lower body 
Body satisfaction

satisfaction than male subjects. Further analysis showed a significant condition by time interaction $(F[1,38]=11.40, \mathrm{p}<0.005)$ but no significant gender by condition by time

interaction. The means suggested that regardless of gender all subjects responded differently to the two conditions and felt more satisfied with their bodies after viewing the fat pictures and similarly all felt less satisfied with their bodies after viewing the thin pictures.

\section{2) Body Size Estimation}

The means of body size estimation using the marking technique are shown in Table 4.

- Insert Table 4 about here -

\section{i) Chest/Bust Estimation}

The results showed a main effect of gender $(F[1,38]=15.95, \mathrm{p}<0.001)$ and time $(\mathrm{F}[1,38]=$ 4.52, $\mathrm{p}<0.05)$, but no main effect of condition suggesting that male subjects estimated their chests to be bigger than female subjects both before and after the experimental manipulation. The results also showed a significant condition by time interaction $(F[1,38]=15.57$, $p<0.001)$ but no gender by condition by time interaction. Examination of the means suggests that regardless of gender all subjects rated themselves as larger after the thin pictures and smaller after the fat pictures.

\section{ii) Waist Estimation}

The results showed a main effect of gender $(F[1,38]=16.66, p<0.001)$ and condition $(F$ $[1,38]=4.82, \mathrm{p}<0.05)$, no main effect of time, a significant condition by time interaction $(\mathrm{F}$ $[1,38]=21.87, \mathrm{p}<0.001)$ but no gender by condition by time interaction. The means suggest 
Body satisfaction

that, overall, female subjects estimated their waists to be smaller than the male subjects, and that all subjects, regardless of gender, showed a decrease in estimation of waist size after viewing the fat pictures and an increased estimation of waist size after viewing the thin pictures.

\section{iii) Hips Estimation}

Analysis showed no main effects of gender, condition or time, a significant condition by time interaction $(\mathrm{F}[1,38]=4.72, \mathrm{p}<0.05)$ but no gender by condition by time interaction.

Examination of the means indicated that regardless of gender all subjects responded differently to the two conditions and estimated their hips as larger after the thin pictures and smaller after the fat pictures.

The final analysis examined the role of restrained eating in determining these changes to the media images. Subjects were categorised as either restrained $(n=18$, mean score; $14.22 \pm$ 3.37) or unrestrained eaters $(n=22$, mean score; $28.00 \pm 6.28)$ according to a median split on their scores on the restrained eating section of the DEBQ (median score; 21.00). The results were then analysed by including restraint level (high vs low) as a between subject variable in the MANOVA. The results showed no significant condition by time by sex by restraint levels interaction for either the visual analogue scales measures of body satisfaction, the body silhouettes measure or body size estimation suggesting that restraint level was not a significant factor in determining the different profile of response to the pictures in both conditions.

\section{Discussion}

The present study aimed to evaluate the effect of acute exposure to both thin and fat media 
Body satisfaction

pictures on the body satisfaction of men and women. The results suggest that overall men report greater body satisfaction than women. In particular, the male subjects rated themselves as less fat, more sexy, more toned, and more fit than the female subjects. In addition, the men showed overall higher body satisfaction when measured using the body shape questionnaire and in terms of a smaller discrepancy between their preferred size and ratings of their present body size. This supports previous reports of gender differences of body satisfaction (Brodie, Slade and Riley, 1991., Rozin and Fallon, 1988., Klesges, Mizes and Klesges, 1987., Jeffrey, Adlis, Forster, 1991). In addition, these results provide insights into the higher prevalence of dieting behaviour and eating disorders in women (Jeffrey, Adlis and Forster, 1991., Crisp, 1984).

The results also support the predicted effects of acute exposure to media images on body satisfaction with all subjects showing a deterioration in body image in terms of factors such as fatness, feeling sexy, attractiveness, feeling fit and toned and changes in the discrepancy between preferred and actual estimations of body size following pictures of thin individuals. This provides support for previous research indicating that acute exposure to thin models may exacerbate body dissatisfaction in patients suffering from eating disorders (Waller, Hamilton, Shaw, 1992., Hamilton and Waller, 1993). Furthermore, the results indicate an improvement in factors related to body satisfaction following pictures of overweight individuals supporting suggestions that the media has an important role in determining concerns for weight and shape (Silberstein, Streigel-Moore and Rodin, 1987., Garner et al, 1980., Morris, Cooper and Cooper, 1989). However, many of these changes in body satisfaction were found in subjects of both gender. This suggests that although overall men may show higher body satisfaction than 
Body satisfaction

women, they are still sensitive to media images of cultural norms and respond to these images in a similar direction to women, in particular in terms of feelings of attractiveness and sexiness. It is possible that these attributes are of equal concern to both men and women and therefore both genders respond to images with equivalent changes in these variables. Some gender differences were, however, reported in body satisfaction changes to the media images, with the female subjects showing greater improvement than the male subjects in their ratings of feeling fat and toned following the fat pictures and greater deterioration in these factors following the thin pictures. Perhaps fatness and feeling toned are particularly pertinent to women and are therefore more sensitive to manipulation. This supports research indicating that women are more concerned with weight per se than men who tend to be more concerned with strength (Franzoi and Shields, 1984). In addition, if body image is a product of comparisons between self and others, as predicted by social comparison theory and theories of social norms, characteristics such as fatness and feeling toned may be more pertinent to women and more sensitive to manipulation as these characteristics are central to such social comparisons.

The results from the present study have implications both for understanding the etiology of body dissatisfaction and for possible treatment interventions. If acute exposure to media images of stereotypical attractiveness can cause a deterioration in body satisfaction, it is possible that chronic exposure is in part responsible for the increasing concerns for weight and shape found in western cultures. However, the results from the present study indicate that body satisfaction may be sensitive to exposure to images of different types of body size. Perhaps, interventions could be developed involving the explicit use of media images both to improve body satisfaction and explore why such images have such an immediate effect on the way both men and women perceive their body size. Therefore, media images may not be an 
Body satisfaction

undesirable social factor which should be eradicated but a useful tool for clinical practice.

\section{References}

Agras, W.S., Kirkely, B.G. (1986). Bulimia: theories of etiology. Handbook of eating

disorders. Physiology, psychology and treatment of obesity, anorexia and bulimia, New York: Borei Books.

Askevold, F. (1975). Measuring body image: preliminary report of a new method.

Psychotherapy and Psychosomatics, 26, 71-77.

Ben-Tovim, D.L., Walker, M.K., Fok, D., Yap, E. (1989). An adaptation of the Stroop task for measuring shape and food concerns in eating disorders: A quantitative measure of psychopathology? International Journal of Eating Disorders, 8, 681-687.

Bowden, P.K., Touyz, S.W., Rodriguez, P.J., Hensley, R., Beumont, P.J.V. (1989). Distorting patient or distorting instrument? Body shape disturbance in patients with anorexia nervosa and bulimia. British Journal of Psychology, 155, 196-201. 
Body satisfaction

Brennan, N., Kevenew, J. (1985). Anthropometry and body image in a selected sample of adolescent girls. Irish Journal of Medical Science, 154, 220-227.

Brodie, D.A., Slade, P.D., Riley, V.J. (1991). Sex differences in body image perceptions. Perceptual and Motor Skills, 72, 73-74.

Brownell, K.D. (1991). Dieting and the search for the perfect body: Where physiology and culture collide. Behaviour Therapy, 22, 1-12.

Bruch, H. (1974). Eating Disorders: Anorexia, Obesity and the person within. London and Boston, Routledge and Kegan Paul.

Carroll, D., Gleeson, C., Ribsby, B., Dugdale, A.E. (1986). Body build and the desire for slenderness in young people. Australian Paediatric Journal, 22, 121-125.

Cooper, P.J., Taylor, M.J., Cooper, Z,. Fairburn, C.G. (1987). The Development and Validation of the Body Shape Questionnaire. International Journal of Eating Disorders. 6, 485-494.

Counts, C.R., Adams, H.E. (1985). Body image in bulimic, dieting and normal females. Journal of Psychopathology and Behavioural Assessment, 7, 289-300.

Crisp, A.H. (1984). The Psychopathology of Anorexia Nervosa: Getting the 'Heat' out of the System. In (eds) A.J. Stunkard., E. Stellar. Eating and its Disorders, Raven press. New York. 
Body satisfaction

Fairburn, C.G., Cooper, P.J., Cooper, M.J., McKenna, F.P., Anastasiades, P. (1991) Selective information processing in bulimia nervosa. International Journal of Eating Disorders, 10 , 515-522.

Franzoi, S.L., Shields, D. (1984). Journal of Personalty Assessment, 48, 173-180.

Furnham, A., Radley, S. (1989). Sex differences in the perception of male and female body shapes. Personality and Individual Differences, 10, 653-662.

Furnham, A., Alibhai, N. (1983). Cross cultural differences in the perception of female body shapes. Psychological Medicine, 13, 829-837.

Garner, D.M., Garfinkel, P.E., Schwartz, D., Thompson, M. (1980). Cultural Expectations of thinness in women. Psychological Reports. 47 (2). 483-491.

Glassner, B. (1988). Bodies: why we look the way we do and how we feel about it. New York: Putnam.

Halmi, K.A., Goldberg, S.C., Cunningham, S. (1977) Perceptual distortion of body image in adolescent girls: Distortion of body image in adolescence. Psychological Medicine. 7, 253-257.

Hamilton, K., Waller, G. (1993) Media influences on body size estimation in anorexia and bulimia: an experimental study. $\quad$ British Journal of Psychiatry, 162, 837-840. 
Body satisfaction

Herman C.P. and Polivy J.A. (1984). A Boundary Model for the Regulation of Eating. In : Eating and its Disorders. A.J. Stunkard and E. Stellar (Eds), Raven Press. 141-156.

Herman C.P. and Mack D. (1975). Restrained and Unrestrained Eating. Journal of Personality. 43, 646-660.

Hill, A.J., Draper, E., Stack, J. (1994). A weight on children's minds: body shape dissatisfactions at 9 years old. International Journal of Obesity, 18, 383-389.

Hsu, L.K.G., Sobkiewicz, T.A. (1991) Body image disturbance: Time to abandon the concept for eating disorders. International Journal of Eating Disorders. $10,15-30$.

Jeffrey, R.W., Adlis, S.A., Forster, J.L. (1991). Prevalence of dieting among working men and women: the healthy worker project. Health Psychology, 10, 274-281.

Klesges, R.C., Mizes, J.S., Klesges, L.M. (1987). Self help dieting strategies in college males and females. International Journal of Eating Disorders, 6, 409-417.

Morris, A., Cooper, T, Cooper, P.J. (1989). The Changing Shape of female fashion models. International Journal of Eating Disorders. 8, 593-596.

Ogden, J., Wardle, J. (1991). Cognitive and emotional responses to food. International Journal of Eating Disorders, 10, 297-311. 
Body satisfaction

Ogden, J., Greville, L. (1993). Cognitive changes to preloading in restrained and unrestrained eaters as measured by the Stroop task. International Journal of Eating Disorders, 14, 185-195.

Ogden, J. (1992). Fat Chance! The Myth of Dieting Explained. Routledge UK / USA / Canada.

Ogden, J. (1993). The Measurement of Restraint - confounding success and failure? International Journal of Eating Disorders, 13, 69-76.

Orbach S. (1978). Fat is a Feminist issue - the Anti-diet Guide to Weight loss. New York and London, Paddington Press.

Pierloot, R., A., Houben, N.E. (1978). Estimation of body dimensions in anorexia nervosa. Psychological Medicine, 8, 317-324.

Rozin, P., Fallon, A. (1988). Body image, attitudes to weight, and misperception of figure preferences of the opposite sex; a comparison of men and women in two generations. Journal of Abnormal Psychology, 97, 342-345.

Silberstein, B., Streigel-Moore, R.H., Rodin, J (1987). Feeling fat: a woman's shame. The role of shame in symptom formation, Hillsdale, N.J. Erlbaum.

Slade, P., Russell, G. (1973). Awareness of body dimensions in Anorexia Nervosa: cross sectional and longitudinal studies. Psychological Medicine, 3, 188-199. 
Body satisfaction

Sumner, A., Waller, G., Killick, S., Elstein, M. (1993). Body image distortion in pregnancy: a pilot study of the effects of media images. Journal of Reproductive and Infant Psychology, 11, 203-208.

Thompson, J.K., Thompson, C.M. (1986) Body size distortion and self esteem in asymptomatic normal weight males and females. International Journal of Eating Disorders. $5,1061-1068$.

Van Strien T., Frijters J.E., Bergers G.P. and Defares P.B. (1986). Dutch eating behaviour questionnaire for the assessment of restrained, emotional, and external eating behaviour. International Journal of Eating Disorders. 5, 295-315.

Waller, G., Hamilton, K., Shaw, J. (1992). Media influences on body size estimation in eating disordered and comparison subjects. British Review of Bulimia and Anorexia Nervosa., 6, 81-87.

Wardle, J., Beales, S. (1986). Restraint, body image and food attitudes in children from 12 to 18 years. Appetite, $7,209-217$.

Wingate, B., Christie, M.J. (1978). Egostrength and body image in anorexia nervosa. Journal of Psychosomatic Research, 22, 201-204. 
Body satisfaction

$\underline{\text { Table } 1 \text { - Profile of subjects (means and SDs) }}$

\begin{tabular}{||l|l|l||}
\hline & Males $(\mathrm{n}=20)$ & Females $(\mathrm{n}=20)$ \\
\hline Age (yrs) & $20.8 \pm 0.69$ & $20.8 \pm 1.32$ \\
\hline Restrained eating & $17.25 \pm 7.12$ & $26.8 \pm 6.84^{*}$ \\
\hline BSQ & $51.95 \pm 13.59$ & $82.85 \pm 18.73^{*}$ \\
\hline
\end{tabular}

* significant effect of gender $(p<0.05)$ 
Body satisfaction

$\underline{\text { Table } 2 \text { - Body satisfaction - visual analogue scales (means and SDs) }}$

\begin{tabular}{|c|c|c|c|c|c|c|c|c|}
\hline & \multicolumn{4}{|c|}{ Thin pictures } & \multicolumn{4}{|c|}{ Fat pictures } \\
\hline & \multicolumn{2}{|l|}{ Time 1} & \multicolumn{2}{|c|}{ Time 2} & \multicolumn{2}{|l|}{ Time 1} & \multicolumn{2}{|l|}{ Time 2} \\
\hline & $\mathrm{M}$ & F & $\mathrm{M}$ & F & $\mathrm{M}$ & $\mathrm{F}$ & $\mathrm{M}$ & $\mathrm{F}$ \\
\hline Fat*\# & $\begin{array}{l}24.7 \pm \\
18.61\end{array}$ & $\begin{array}{l}37.9 \pm \\
18.67\end{array}$ & $\begin{array}{l}26.8 \pm \\
19.25\end{array}$ & $\begin{array}{l}45.7 \pm \\
15.24\end{array}$ & $\begin{array}{l}23.0 \pm \\
19.2\end{array}$ & $\begin{array}{l}44.5 \pm \\
16.9\end{array}$ & $\begin{array}{l}21.7 \pm \\
18.37\end{array}$ & $\begin{array}{l}28.9 \pm \\
15.59\end{array}$ \\
\hline Sexy* & $\begin{array}{l}45.1 \pm \\
19.2\end{array}$ & $\begin{array}{l}31.6 \pm \\
21.19\end{array}$ & $\begin{array}{l}44.7 \pm \\
18.63\end{array}$ & $\begin{array}{l}28.7 \pm \\
16.27\end{array}$ & $\begin{array}{l}46.5 \pm \\
22.13\end{array}$ & $\begin{array}{l}31.6 \pm \\
21.7\end{array}$ & $\begin{array}{l}51.8 \pm \\
22.15\end{array}$ & $\begin{array}{l}39.1 \pm \\
20.74\end{array}$ \\
\hline $\begin{array}{l}\text { Attract } \\
*\end{array}$ & $\begin{array}{l}51.4 \pm \\
15.67\end{array}$ & $\begin{array}{l}39.7 \pm \\
17.75\end{array}$ & $\begin{array}{l}47.9 \pm \\
16.97\end{array}$ & $\begin{array}{l}38.0 \pm \\
19.55\end{array}$ & $\begin{array}{l}48.7 \pm \\
19.01\end{array}$ & $\begin{array}{l}38.1 \pm \\
19.55\end{array}$ & $\begin{array}{l}52.3 \pm \\
18.5\end{array}$ & $\begin{array}{l}47.1 \pm \\
17.64\end{array}$ \\
\hline Toned & $43.2 \pm$ & $26.9 \pm$ & $42.7 \pm$ & $24.7 \pm$ & $46.3 \pm$ & $32.2 \pm$ & $50.6 \pm$ & $47.6 \pm$ \\
\hline
\end{tabular}


Body satisfaction

\begin{tabular}{||l|l|l|l|l|l|l|l|l||}
\hline \hline$* \#$ & 20.94 & 12.7 & 19.42 & 14.43 & 18.79 & 16.46 & 18.5 & 14.14 \\
\hline Fit* & $49.7 \pm$ & $32.1 \pm$ & $46.0 \pm$ & $29.8 \pm$ & $49.7 \pm$ & $35.5 \pm$ & $51.2 \pm$ & $45.6 \pm$ \\
& 25.2 & 12.14 & 25.41 & 13.79 & 24.99 & 15.98 & 26.2 & 13.16 \\
\hline
\end{tabular}

* significant condition $\mathrm{x}$ time interaction $(\mathrm{p}<0.01)$

\# significant condition $\mathrm{x}$ time $\mathrm{x}$ gender interaction $(\mathrm{p}<0.01)$

$\underline{\text { Table } 3 \text {-Body satisfaction -body silhouettes (means and SDs) }}$

\begin{tabular}{|c|c|c|c|c|c|c|c|c|}
\hline & \multicolumn{4}{|c|}{ Thin pictures } & \multicolumn{4}{|c|}{ Fat pictures } \\
\hline & \multicolumn{2}{|c|}{ Time 1} & \multicolumn{2}{|c|}{ Time 2} & \multicolumn{2}{|c|}{ Time 1} & \multicolumn{2}{|c|}{ Time 2} \\
\hline & M & $\mathrm{F}$ & M & $\mathrm{F}$ & M & $\mathrm{F}$ & $\mathrm{M}$ & $\mathrm{F}$ \\
\hline Now $*$ & $\begin{array}{l}6.0 \pm \\
1.65\end{array}$ & $\begin{array}{l}6.3 \pm \\
1.03\end{array}$ & $\begin{array}{l}6.2 \pm \\
1.64\end{array}$ & $\begin{array}{l}6.5 \pm \\
0.89\end{array}$ & $\begin{array}{l}6.05 \pm \\
1.67\end{array}$ & $\begin{array}{l}6.55 \pm \\
0.83\end{array}$ & $\begin{array}{l}5.9 \pm \\
1.45\end{array}$ & $\begin{array}{l}6.4 \pm \\
0.82\end{array}$ \\
\hline Prefer & $6.2 \pm$ & $5.55 \pm$ & $6.1 \pm$ & $5.45 \pm$ & $6.1 \pm$ & $5.6 \pm$ & $6.0 \pm$ & $5.8 \pm$ \\
\hline
\end{tabular}


Body satisfaction

\begin{tabular}{||l|l|l|l|l|l|l|l|l||}
\hline \hline & 0.09 & 1.05 & 0.85 & 0.99 & 0.97 & 0.82 & 1.03 & 0.69 \\
\hline Body* & $0.2 \pm$ & $-0.75 \pm$ & $-0.10 \pm$ & $-1.10 \pm$ & $0.05 \pm$ & $-0.95 \pm$ & $0.1 \pm$ & $-0.6 \pm$ \\
satis. & 1.51 & 0.7 & 1.37 & 0.96 & 1.35 & 0.89 & 1.07 & 0.6 \\
\hline
\end{tabular}

$($ Body Satisfaction $=$ Prefer-Now $)$

* significant condition $\mathrm{x}$ time interaction $(\mathrm{p}<0.01)$

$\underline{\text { Table } 4 \text { - Body size estimation (means and SDs) }}$

\begin{tabular}{||l|l|l|l|l||}
\hline \multicolumn{2}{|l|}{ Thin pictures } & \multicolumn{2}{l|}{ Fat pictures } \\
\cline { 2 - 5 } & Time 1 & Time 2 & Time 1 & Time 2 \\
\hline
\end{tabular}


Body satisfaction

\begin{tabular}{||l|l|l|l|l|l|l|l|l||}
\cline { 2 - 9 } & \multicolumn{1}{|c|}{$\mathrm{M}$} & \multicolumn{1}{|c|}{$\mathrm{F}$} & $\mathrm{M}$ & $\mathrm{F}$ & $\mathrm{M}$ & $\mathrm{F}$ & $\mathrm{M}$ & $\mathrm{F}$ \\
\hline Chest / & $35.1 \pm$ & $29.13 \pm$ & $34.38 \pm$ & $31.3 \pm$ & $35.25 \pm$ & $30.08 \pm$ & $33.2 \pm$ & $28.43 \pm$ \\
bust * & 5.12 & 2.79 & 4.29 & 3.47 & 4.84 & 5.02 & 5.29 & 4.59 \\
\hline Waist * & $30.73 \pm$ & $25.6 \pm$ & $31.35 \pm$ & $28.33 \pm$ & $31.53 \pm$ & $25.85 \pm$ & $28.93 \pm$ & $25.6 \pm$ \\
& 3.96 & 3.29 & 4.62 & 4.08 & 4.08 & 3.55 & 3.48 & 4.08 \\
\hline Hips * & $34.57 \pm$ & $33.38 \pm$ & $35.4 \pm$ & $36.45 \pm$ & $32.92 \pm$ & $34.6 \pm$ & $34.95 \pm$ & $33.3 \pm$ \\
& 4.85 & 6.95 & 5.18 & 5.05 & 9.38 & 4.71 & 4.86 & 5.70 \\
\hline
\end{tabular}

* significant condition $\mathrm{x}$ time interaction $(\mathrm{p}<0.01)$ 